\title{
Ethics, the Illegality of Physician Assisted Suicide in the United States, and the Role and Ordeal of Dr. Jack Kevorkian before His Death
}

\author{
Hengameh M. Hosseini ${ }^{1}$ \\ ${ }^{1}$ Health Administration, School of Public Affairs, Penn State University- Harrisburg, PA, USA \\ Correspondence: Hengameh M. Hosseini, Health Administration, School of Public Affairs, Penn State \\ Harrisburg, Middletown, PA 17057, USA. Tel: 1-717-948-6049. E-mail: huh19@psu.edu
}

Received: September 4, 2012 Accepted: October 22, 2012 Online Published: November 26, 2012

doi:10.5539/res.v4n5p203

URL: http://dx.doi.org/10.5539/res.v4n5p203

\begin{abstract}
The paper tries to argue that physician-assisted suicide (PAS), which is opposed by the AMA and all US states except Oregon, is a moral and ethical dilemma that faces physicians, ethicists, legal experts, and others. To demonstrate this, the various dimensions of the debate are explored. This is accomplished by discussing the legal, ethical, medical and political ordeals of its most infamous practitioner, Dr. Jack Kevorkian of Michigan (1928-2011).

As the paper argues, Dr. Kevorkian's belief in the practice of PAS led him to assist in the suicide of James Adkins in 1998. This began his legal problems, which lasted for about ten years (while continuing this practice, causing the state of Michigan to pass stricter laws against PAS). However, it was his more active administration of the suicide of Thomas York (who had Lou Gehrig's disease), and its demonstration on CBS' 60-Minutes program, that led to his most severe legal ordeal in 1998 that landed him a prison sentence of 10 to 25 years (of which he served 8).

In the paper, various ethical, moral, and legal arguments, evoked by ethicists, philosophers and legal experts are presented. However, the paper begins with the ordeal of Dr. Kevorkian and the reaction to the 60-Minutes piece by the media, religious authors, and others are presented.
\end{abstract}

Keywords: physician assisted suicide, Dr. Kevorkian, ethics, legal dilemma

\section{Introduction}

The classical version of the Hippocratic Oath in medicine has various requirements for physicians. Among those, the physician is required to state that: "I will neither give a deadly drug to anybody if asked for it, nor will I make a suggestion to that effect." However, in spite of that oath, the ancient Greeks wrestled with the question of whether, in some cases, people would be better off dead (Levine, 1997). In fact, the ancient Greeks were the first to debate the practice of euthanasia - a Greek word that literally means "happy death."

During the last few decades, physicians, lawyers, philosophers, and judges have discussed questions regarding withholding medical treatment in certain situations. As Carol Levine (1997) argued, their deliberations have resulted in a broad consensus that competent adults have the right to make decisions about their medical care, even if those decisions result in death. These discussions have also given rise to debates about euthanasia (i.e., a situation in which the physician acts directly to end a patient's life) and physician-assisted suicide (i.e., suicide in which the physician merely provides a patient with a means of death) - both of which take place for various reasons and can be considered merciful.

The following will discuss the ethics and legality of physician-assisted suicide (PAS), an issue which gained national attention in the late 1980s with the media coverage of Dr. Jack Kevorkian's medical practices. Dr. Kevorkian, a Michigan medical pathologist, believed that physician-assisted suicide was a just practice, and became an outspoken advocate for the cause. Of course, this practice is opposed by the American Medical Association (AMA). According to New York Times, "The American Medical Association in 1995 called 'Jack Kevorkian 'a reckless instrument of death 'who' poses a great threat to the public." His beliefs and activities embroiled him in a number of serious legal battles, beginning with his assistance of the 1989 suicide of Janet Adkins. Despite his legal problems, Dr. Kevorkian continued to practice PAS for nearly ten years. In 1998, however, when it was discovered that he had administered a lethal injection to Thomas York, who was suffering 
from Lou Gehrig's disease, and videotaped the death to be broadcast on CBS's 60 Minutes, Kevorkian was forced to stand trial. He was found guilty of murder and sentenced to 10-25 years in prison. Because he administered the lethal injection, rather than simply providing the person with the means to kill, and because he also videotaped the act, Kevorkian faced more serious repercussions, and the case of Thomas Youk proved even more controversial than that of Adkins.

It can be argued that although physician-assisted suicide is opposed by the American Medical Association (AMA), it still remains a moral/ethical dilemma. Physician-assisted suicide (which is different from that which took place in the death of Youk) may be defended on the basis of certain ethical principles, despite of the fact that it is only legal in the state of Oregon. However, because PAS presents a moral/ethical dilemma, we can also oppose it on the basis of certain other ethical principles. Both the relevant ethical principles, and the ethical arguments for and against PAS, will be discussed in the fourth and fifth sections. However, before embarking upon these discussions, the PAS-related activities in which Kevorkian was involved and the debates and discussion they generated will be presented. This presentation will be followed with a discussion of the reaction of various people and organizations (the media, the Catholic Church in Michigan, and others) to 60 Minutes' broadcasting of the suicide videotape of Thomas Youk. The discussions will conclude with a proposal for the (very extreme) conditions under which interested parties may deem PAS necessary.

\section{Dr. Kevorkian's PAS Activities and the Law: How Did He End Up in Prison?}

Dr. Jack Kevorkian of Pontiac, Michigan (the son of Armenian refugees) began his Physician-assisted suicide-related activities in the 1980s, when he built a machine that could administer a narcotic followed by a lethal dose of potassium chloride to patients, ensuring a swift death. Dr. Kevorkian believed that people have a right to avoid a lingering, miserable death by ending their lives with help from a physician who can ensure that they die peacefully and with dignity. Kevorkian hoped to make PAS a practice that is accepted by the medical community, which would, of course, require the practice's legalization. A full appreciation for the obstacles Kevorkian has faced in achieving these goals demands an understanding of how physician-assisted suicide is currently viewed by the United States legal system.

In most states in the United States any assistance or aiding in a suicide is a crime. The state of Oregon is the only US state among the fifty states that has legalized physician- assisted suicide. Of course, even Oregon's right-todie law has been challenged by the federal government in United States federal courts. As recently as May 2004, in a 2-to-1 ruling, the $9^{\text {th }}$ U.S. Circuit Court of Appeals in San Francisco decided that Attorney General John Aschcroft could not try to undermine the Oregon's Death with Dignity Act (McCall, 2004).

Several other major court decisions that hold significant implications for PAS have recently been made. First, the Ninth U.S. Circuit Court of Appeals determined that individuals have a right to choose how and when they die (Braddock, 2001). Also, the Second U.S. Circuit Court found a New York state law on PAS in conflict with the $14^{\text {th }}$ Amendment. According to this decision, no state shall "deny any person within its jurisdiction the equal protection of the laws" (Rehnquist, 1997, p.2). The court held that under the New York law, competent patients were being treated differently than incompetent patients. The United State Supreme Court has ruled that there is no constitutional right to assist suicide, and has made a distinction between refusal of treatment and physicianassisted suicide. However, the Supreme Court has also left the decision of whether to legalize PAS up to each individual state (Rehnquist, 1997).

Dr. Jack Kevorkian found his first PAS client in Janet Adkins, a 54-year Alzheimer's patient from Portland, Oregon, in 1989 ("Newsmakers: Jack Kevorkian”, n.d.). Kevorkian's assistance of Adkins' suicide brought about a great deal of media attention and debate about both euthanasia and PAS, and Kevorkian was charged with murder in his home state of Michigan (Oakland County) in connection with her death. But the Oakland County District Court dropped charges on December 13, 1990, after a two-day preliminary hearing. The court ruled that Kevorkian did not break any law by helping Janet Adkins to commit suicide, on the grounds that in Michigan there existed no law outlawing suicide or the medical assistance of it. Though the charges were dismissed, the case brought up a number of issues of great consequences to the practice of PAS that the court was unable to resolve. The issues outlined in court documentation include questions of whether Adkins had in fact given her informed consent to the suicide; the fact that Dr. Kevorkian did not have an established professional relationship with her, and whether that was legally problematic; the fact that Adkins was not terminally ill; the whole issue of whether or not a person actually posses the right to die; and discussions on the limits of autonomy (The People Versus Kevorkian, 1991).

Although he faced many serious legal difficulties, Dr. Kevorkian managed to stay out of prison for about 10 years after Adkins' death. Kevorkian's luck finally changed in 1998, however, when, in an unprecedented move, 
he directly administered a series of lethal injections to Thomas Youk, rather than simply providing him the means to kill himself as he had done for patients in the past. Kevorkian videotaped Youk's injections and death with the intention of broadcasting the tape on national television. The videotaped death of Thomas Youk was shown on CBS's 60 Minutes two months later. Within days of that 60 Minutes broadcast, Dr. Kevorkian was again charged with murder in the State of Michigan.

Legally and otherwise, the Youk case was more serious than the Janet Adkins case. First, in 1998, prior to Youk's death, Michigan had passed a new law outlawing physician-assisted suicide. Secondly, by directly giving Thomas Youk a lethal injection, Dr. Kevorkian had, in effect, crossed the line from a less active (and perhaps inflammatory) role in a case of PAS to a more active role in a case of euthanasia. Third, by videotaping the act and showing it on national television, he had angered opponents of PAS throughout the nation. As Assistant Oakland County (Michigan) Prosecutor John Skrzynski told reporters, "If Jack Kevorkian had not videotaped this, no one would have ever known it had happened... Jack Kevorkian brought it on himself" (Kahn, 1998, p.1). The anger in response to Kevorkian's bold move is also obvious in an opinion piece by physician Jeffrey Kahn: "In fact, debate about his decisions to videotape the death and to subsequently appear on 60 Minutes threatens to overshadow any meaningful national policy discussion of assisted death" (1998).

In the court, Kevorkian's defense was that: "there are certain acts that by sheer common sense are not crimes" (Kahn, 1998, p.1). But, the above-mentioned prosecutor who argued the case told the jury that: "Kevorkian came like a medical hit man in the night with a bag of poison to do his job" (Kahn, 1998).

Although Thomas Youk's widow had begged the judge to show mercy, on April 13,

1999, Michigan Judge Jessica Cooper sentenced the (then) 70-year old Dr. Jack Kevorkian to 10-25 years in prison for the videotaped death of 52-year-old Thomas Youk (who was suffering with Lou Gehrig's disease). Interestingly enough, Thomas Youk's videotaped death took place less than three weeks after Michigan enacted a law making assisted suicide a felony punishable by up to five years in prison. (Again, the death of Thomas Youk was viewed to be more serious than the simple case of physician - assisted suicide, perhaps explaining why he was sentenced to more than 5 years). It is worth mentioning that Dr.Kevorkian served only 8 years of that 10-25 years sentence. For, he was released on parole on June 1, 2007 on the condition that he would not offer suicidal advice to any other person. He died four years later in 2011.

\section{The Various Reactions to the " 60 Minutes" Airing of Thomas Youk's Death}

Kevin Todesco, a spokesman for 60 Minutes articulated his belief that the televised report performed a valuable public service. To Kevin Todesco, "Mike Wallace's report on Dr. Kevorkian goes to the core of an important national debate" (Case Histories, 1998). Mike Wallace's 60 Minutes report of the death of Thomas Youk was also praised by Hemlock Society USA, a death with dignity organization. Part of the organization's statement about the 60 Minutes episode reads: "The CBS program brought the issue of end of life choice dramatically into the nation's living rooms. The dramatic and moving scene of dying, gracefully and peacefully, with the help of a physician illustrates the need to legalize the practice of medical assistance in dying as part of the continuum of care at the end of life" (Case Histories, 1998).

However, there was also a great deal of negative reaction to the 60 Minutes report. For one thing, not all CBS affiliates in the nation aired the segment of the 60 Minutes that contained Mike Wallace's piece. One such station was the Houston CBS affiliate KHOU-TV. According to the station's Vice President: "Normally, at this time, we would be broadcasting 60 Minutes...however, the first segment on tonight's broadcast involved an interview with Dr. Jack Kevorkian and a potentially graphic video involving the issue of euthanasia..." He continued, "It is the position of KHOU - TV, Channel 11, and the Belu Corp., our owners, that because this video shows the injection and the individual's moment of death, that it was not appropriate for this time period or broadcast television" (Case Histories, 1998).

Following the 60 Minutes report, there were numerous negative reactions from commentators of both electronic and printed media. Denver Post critic Jane Ostrow wrote soon after the broadcast: "Death on TV Interview, wrap up, and now a word from our sponsor...Sunday's decision by the badly tarnished CBS represents a new low" (1998, p.5). In his Baltimore Sun column "Death comes to Prime Time," critic David Zvrawik wrote: "I do not think it is categorically wrong to show someone die on television, but is wrong to do it the way 60 Minutes did...CBS did not humanize him before exploiting him and violating one of the last realms of privacy in our media crazed culture..." (Case Histories, 1998).

Negative reactions were also apparent in religiously-inclined circles. For example, as American Life League President Judie Brown said: "The execution of Thomas Youk was cold-blooded murder. God is the author of life, 
Jack Kevorkian is not. He has no authority to violate the Commandment: Thou Shall Not Kill...Lock him up," demanded Judie Brown (Case Histories, 1998). The Archdiocese of Detroit too condemned the broadcast. In a statement issued by Ned McGrath, spokesperson of the Archdiocese, he wrote: "What I saw on my TV screen is a publicity- hungry, unlicensed pathologist kill a visibly troubled, vulnerable man... and make a spectacle of it on national TV. It is a valid question to ask what is next..." (Kahn, 1998).

But what was the reaction from society at large? Two days after the broadcast, CBS pollsters attempted to determine people's reaction to the story. Some of the findings of the poll, which reached more than one thousand adults nationwide, were as follows:

- 19 percent thought Kevorkian should be charged with murder.

- 27 percent said he should be charged with a lesser crime.

- 39 percent felt he should not be punished in any way

- By a nearly two to one margin (61 vs. 30 percent), the people interviewed rejected the argument that a doctor injecting ill person with a lethal dose of considered the same thing as murder (Kahn, 1998).

\section{What Ethical Principles Should Be Applied to Physician-Assisted Suicide?}

Legality aside, all professions should be guided by ethical behavior. As argued by Jennings, Callahan, and Wolf in their Hastings Center Report, "In ethical terms, to be professional is to be dedicated to a distinct set of ideas and standards of conduct. It is to lead to a certain kind of life defined by special virtues and norms of character" (1987, p.25). This is particularly true of the medical profession, since physicians deal with human life. Ethical behavior of physicians especially matters in situations where they have to decide whether or not they should assist patients to commit suicide in very painful situations. However, I do not believe the ethics code of the American Medical Association (AMA) could be a very useful guide (to physicians in this regard). The 1957-1980 version of the AMA code urged patients to be upright and pure in character, and diligent and conscientious in caring for the sick. The 1957-1980 version also endorsed that urging: "Hippocrates commended: modesty, sobriety, patience, promptness, and piety" (Beauchamp \& Childress, 2001, p.31). And, in contrast to its 1847 version (code), it de-emphasized virtues. According to the above authors, the 1980 code "eliminated all traces of the virtues except for the admonition to expose those physicians deficient in character or competence" (Beauchamp and Childress, 2001, p. 31). Or, according to Bruce Jennings, Daniel Callahan, and Susan Wolf (1987), for its part, the American Medical Association in its Principles of Medical Ethics affirms that: "a physician must recognize responsibility not only to patients, but also to society and participate in activities contributing to an improved community" (p.26). Also, concerning the case of physician-assisted suicide, the American Medical Association has generally argued against it, not on the basis of ethical principles, but on the grounds that it undermines the integrity of the medical profession. However, surveys of individual physicians show that half of them find physician-assisted suicide ethically justifiable in certain situations. An additional survey of practicing physicians showed that about 1 in 5 of them will receive a request for PAS sometime in their career. According to the survey indicated, 5 to 20 percent of those requests are eventually honored (McCall, n.p.).

Suicide, assisted or not, can (and should) be viewed from an ethical dimension and point of view. Individuals in pain who seek assistance in suicide are members of the community/society. As such, they are in relationships that are (or should be) governed by ethical duties and behaviors. As a result, I believe, it is a social problem that requires the application of ethical principles relevant to all social relationships. This explains why, as argued by Beauchamp and Childress (2001), the state, religious institutions, and health care professionals have traditionally assumed some jurisdiction to intervene with suicide.

Since the AMA's opposition to PAS is not rooted in specified ethical principles, we should try to utilize ethical principles to determine if PAS can be justified. But, what are the ethical principles that are relevant to physician-assisted suicide? To see whether we should support or oppose physician-assisted suicide (as distinct from euthanasia), we should view four ethical principles. (1) Autonomy, which is respect for the individual self-determination. In the words of Beauchamp and Childress, it is: "A norm of respecting the decision-making capabilities of autonomous persons" (2001, p. 12). (2) Beneficence, which is doing the greatest good possible. According to Beauchamp and Childress (2001), it is a "group of norms for providing benefits and balancing benefits against risks and costs" (p.12). (3) Non-maleficence, which is preventing harm. It is a norm for avoiding the causation of harm. (Beauchamp, 2001). (4) Justice-insuring fairness and equal access to care (i.e. for a fair distribution of benefits, risks, and costs). Of course, it should be remembered that there exist different theories of justice: utilitarian (which emphasizes utility maximization), libertarian (which emphasizes rights to various types 
of liberties), communitarian (that emphasizes the principles and practices of justice that evolve through traditions and practices of the community), and egalitarian (that emphasizes equal access).

\section{Is Physician-Assisted Suicide Ethical?}

To me, utilization of the above ethical principles would not provide a clear answer to this question; ethical principles can be used to both defend and oppose PAS. This explains why many people inside and outside medicine now believe that active physician-assistance to commit suicide for a narrow group of seriously ill and dying patients at their request (Beauchamp and Childress, P.145), while others would opposite it or find it indefensible. In other words, like a moral dilemma, this problem too has two sides to be considered. As such, although in certain restrict cases we may find PAS morally justifiable and thus permissible, we can also find ethical justification for the other side of the argument. What (ethical) arguments can be made in support and in opposition to physician- assisted suicide? First, let us consider the ethical arguments that can be made in support of PAS.

1. Respect for autonomy. Using the ethical principle of (respect for) autonomy, we can argue that decisions about time and circumstances of death are very personal. On that basis, competent persons (when facing unbearable and unending pain) should have the right to choose death. In the words of Claire Andre and Manuel Velasquez, "all persons have a moral right to choose freely what they will do with their lives as long as they inflict no harm to others. This right to choose includes the right to end one's life when we choose" (1987, p.1).

2. Justice. Justice requires that we treat similar cases alike. Competent, terminally ill patients are allowed to hasten their death by refusing treatment. However, for some patients, treatment refusals will not suffice to hasten death. In these situations, the only option is assisted suicide.

3. Non-maleficence - to minimize harm. This can be applied to an extreme case of the unbearable suffering of the patient who seeks PAS. Since, under some extreme circumstances, it may not be possible to relieve suffering of the very sick who seek PAS, the compassionate thing to do might be to allow physician assisted suicide as a response to this unbearable suffering.

4. Individual liberty versus government intervention (as an application of beneficience). I believe society, through its government, has the important interest/responsibility of preserving life. However, it seems to me that the interest and responsibility of society and/or government decreases when very sick individual with unbearable pain and suffering have a strong desire to end his or her own life. An absolute and a complete prohibition of physician-assisted suicides limits individual liberty (Gailey, 2003).

5. Another possible defense is openness of discussion. As stated before, surveys from a variety of sources indicate that today, PAS occurs rather frequently (albeit secretly). According to these surveys, 20 percent of physicians receive a request for PAS sometime during their career, and between 5 and 20 percent of those requests are eventually honored (Herdin, 1995). In such cases, morphine drips typically used for pain relief may be administered in a covert form of assisted suicide. It may be logical to argue that the illegality of physician-assisted suicide (except in Oregon) prevents open discussion in which patients, physicians, ethicists, and others concerned could engage. In other words, legalization of PAS would promote an open discussion among various parties concerned.

\subsection{What Ethical Arguments Can Be Provided in Opposition to PAS?}

1. Sanctity of life. On the basis of both religious traditions and secular ethical principles (such as the principle of autonomy), we can oppose the taking of human life. It can be argued that assisted suicide is morally wrong because it contradicts these religious as well as secular ethical beliefs.

2. Potential for abuse (as an application of justice). It is possible that certain groups of people, lacking access to care and support, may be pushed towards assisted suicide. Or, given the high cost of care in extreme cases, assisted suicide may become a cost-containment strategy. This activity may be encouraged by burdened family members, or by health care providers. On the basis of such abuse, one could oppose physician-assisted suicides (Gailey, 2003).

3.On the basis of the principle of non-maleficence, we can view PAS as a symptom of our failure to develop a better reponse to the fear of intolerable pain or artificial prolongation of life (Hendin, 1995). According to Hendin, "There is a great deal of evidence that doctors are not sufficiently trained in relieving pain and other symptoms in the terminally ill (Hendin, 1995). To him, the medical community has not yet educated the public as to the choices they have in refusing or terminating treatment, nor have medical professionals 
yet learned how best to avoid setting in motion the technology that only prolongs a painful process of dying.

4. Professional integrity - using historical ethical traditions in medicine - which strongly opposes the taking of life. As stated in the Introduction, the Hippocratic Oath opposes the administration of poison to patients. The Hippocratic Oath also states that: "Be of benefit, or at least do not harm" (Edelstein, 1943). The AMA, which opposes assisted suicide, believes the practice of PAS can harm the medical profession.

5. Fallibility of the profession. Some are concerned that physicians may make mistakes in their administration of PAS (an application of justice?). The mistakes may occur because of the uncertainty in diagnosis or prognosis. Thus, justice requires that PAS should be opposed.

\section{Concluding Remarks}

Given the above-mentioned ethical arguments both in support of, and in opposition to, physician-assisted suicide, what are we then to do? Is the practice of PAS ethical, or is it unethical? As I stated before, it seems to be a moral dilemma. The first set of arguments indicates that the practice of physician-assisted suicide is morally right, whereas the second set of arguments indicate that it is morally wrong. This moral dilemma makes the strength of both arguments inconclusive. As a result, there is no perfect ethical solution to this dilemma. However, because we face a moral dilemma, and because PAS might be done secretly even if it is illegal, a conclusive but ethical solution might be warranted. In other words, we might be able to allow PAS in certain rare cases. PAS may appear ethical in certain extreme situations, provided that it satisfies five ethical criteria:

1. The physical or emotional symptoms of the person's illness are, unbearable; that they are so bad that they are not treatable.

2. Psychological support: the patient does not have a network of psychological support that can be comforting.

3. Accuracy of prognosis: every consideration has been made and a second opinion has been sought to verify the diagnosis and prognosis. We have made sure that no mistakes have been made about both diagnosis and prognosis.

4. The degree of patient understanding: the patient understands the disease, its present state, and its expected course.

5. There is no potential of abuse by irresponsible or uncaring family members, or by health providers who have the incentive of lowering costs to encourage patient suicide.

Thus, if the pain is unbearable, and the patient understands these five conditions, then in certain very extreme situations, the practicing PAS can be viewed as more ethical than not helping suffering patients end their lives.

\section{References}

Andre, C., \& Velasquez, M. (1987). Assisted Suicide: A Right or a Wrong?. Issues in Ethics, 1(1), 1-4.

Newsmakers: Jack Kevorkian (nd.). Retrieved June $1, \quad 2004$ from http://abcnews.go.com/reference/bios/kevorkian.html.

Battin, M (1998). Physician Assisted Suicide: Expanding the Debate (Reflective Bioethics). New York: Routledge.

Beauchamp, T., \& Childress, J. (2001). Principles of Biomedical Ethics (5th ed.) New York and Oxford: Oxford University Press.

Braddock, C. (2001, October). Physician Assisted Suicide. Ethics in Medicine. Retrieved May 28, 2004, from http://eduserv.hscer.washington.edu/bioethics/topics/pas.html\#ques1

Case Histories: The TV Rundown, “Kevorkian-assisted Death Airs on '60 Minutes', Broadcast is Attacked and Defended” (1998). Retrieved May 28, 2004, from http://www.tvrundown.com/cases/caskevor.html

Edelstein, L. (1943). The Hippocratic Oath: Text, Translation, and Interpretation. Baltimore: Johns Hopkins Press.

Gailey, E. A. (2003). Write to Death: News Framing of the Right to Die Conflict, from Quinlan's Coma to Kevorkian's Conviction. New York: Praeger Press.

Herdin, H. (1995). Selling Death and Dignity. Hastings Center Report, 25(3). 
Jennings B., Callahan D., \& Wolf, S. (1987). The Professionals: Public Interest and Common Good. Hastings Center Report, 4(13), 20-25.

Kahn, J. (1998, January). Dr. Kevorkian's Latest Release: Death, Crimes and Videotape. Ethics matters. Retrieved May 24 2004 ,

from http://www.bioethics.umn.edu/publications/emarchive/1998.12\%20assisted\%20death.html

Leine, C. (1997). Taking Sides: Clashing Views on Controversial Bioethical Issues (7th ed.). New York: McGraw-Hill.

McCall, W. (2004, May 27). Oregon right-to-die law wins second battle. The Mercury News, pp. A2, A10.

Rehnquist, W. (1997). Washington et al. V. Glucksberg et al., Certiorari to the United States Court of Appeals for the Ninth Circuit. In Supreme Court of the United States Syllabus. Retrieved May 27, 2004, from http://supct.law.cornell.edu/supct/html/96-110.ZS.html 